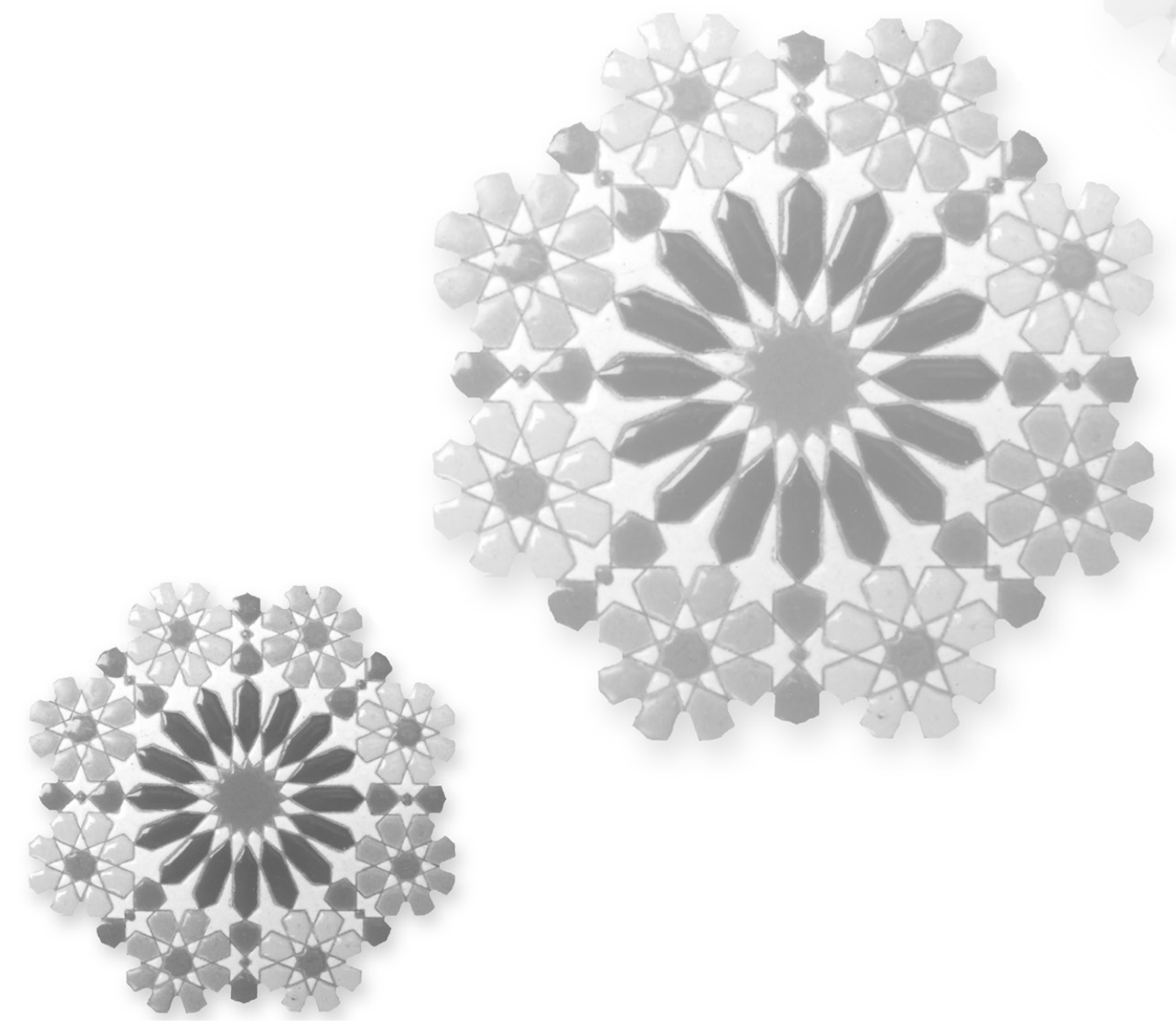




\section{A assistência psiquiátrica a crianças anormais no Hospital Colônia Sant'Ana (Santa Catarina, Brasil, 1940)}

\section{Psychiatric care for abnormal children at the Hospital Colônia Sant'Ana (Santa Catarina, Brazil, 1940s)}

\section{Viviane Trindade Borges}

Professora, Departamento de História/ Universidade do Estado de Santa Catarina. Florianópolis - SC - Brasil

vivianetborges@gmail.com

\section{Sandra Caponi}

Professora, Departamento de Sociologia e Ciência Política/ Universidade Federal de Santa Catarina. Florianópolis - SC - Brasil

sandracaponi@gmail.com

Recebido em 15 maio 2017

Aprovado em 27 fev. 2018
BORGES, Viviane Trindade; CAPONI, Sandra. A assistência psiquiátrica a crianças anormais no Hospital Colônia Sant'Ana (Santa Catarina, Brasil, 1940). História, Ciências, Saúde - Manguinhos, Rio de Janeiro, v.25, n.4, out.-dez. 2018, p.1239-1259.

Resumo

O artigo apresenta pesquisa centrada na assistência psiquiátrica destinada a crianças e jovens ditos anormais em Santa Catarina. Inicialmente, analisase o surgimento da ideia de "criança perigosa", ou da categoria "menor", a partir da discussão de Foucault sobre a noção de "indivíduo perigoso", para então abordarem-se as dificuldades apresentadas na institucionalização da minoridade anormal em Santa Catarina. A seguir, são questionados os vínculos existentes entre as teorias que permitem identificar as crianças ditas anormais com as ideias eugênicas. Por fim, problematiza-se a dinâmica institucional que envolvia os menores ditos anormais internados no Hospital Colônia Sant'Ana na década de 1940.

Palavras-chave: psiquiatria; infância; menores; anormais.

Abstract

Research into the psychiatric care for socalled abnormal children and youths in the Brazilian state of Santa Catarina is presented. The emergence of the idea of the "dangerous child" or the category of "minor" is discussed, drawing on Foucault's discussion of the notion of the "dangerous individual."This is followed by a presentation of the difficulties faced in the institutionalization of abnormal minors in the aforementioned state. The links between theories that enable so-called abnormal children to be identified and the ideas of eugenics are then questioned. Finally, the institutional dynamics involving so-called abnormal children admitted to the Hospital Colônia Sant'Ana in the 1940s are scrutinized.

Keywords: psychiatry; childhood; minors; abnormal. 


\section{A noção de criança perigosa e a criança anormal}

Em 1981, Foucault (2014) realizou em Louvain, Bélgica, um curso intitulado "Fazer o mal, dizer a verdade: a função da confissão na justiça", no qual retoma algumas ideias que já tinham sido enunciadas no texto "A evolução da noção de 'indivíduo perigoso' na psiquiatria legal do século XIX" (Foucault, 1996), publicado nesse mesmo ano. O que se propõe aqui, fazendo um leve deslocamento em relação a esses textos, é analisar o lugar que ocupa outra noção, não mais a de "indivíduo perigoso", mas a de "infância ou criança perigosa", a partir da noção de "criança anormal", que surge nas últimas décadas do século XIX e no início do século XX e se articula em torno de duas figuras: a criança psiquiatricamente anormal e a criança delinquente.

Como se pretende mostrar aqui, analisando os documentos do Hospital Colônia Sant'Ana (HCS), hospital psiquiátrico situado na cidade de São José, em Santa Catarina, as velhas estratégias do século XIX mantiveram-se quase inalteradas ao longo da primeira metade do século XX. Criou-se, assim, um verdadeiro "dispositivo de segurança" por meio da articulação entre o discurso psiquiátrico e o discurso jurídico em torno de crianças consideradas portadoras de desvios da normalidade.

A institucionalização da psiquiatria em Santa Catarina, como proposta de intervenção estatal, teve início em 1941, com a criação do HCS. Até então havia dois hospitais psiquiátricos no estado, o Asilo de Azambuja (1910) e o Hospital Dr. Schneider (1923), instituições que não prestavam atendimento especializado, possuindo apenas um caráter asilar. O HCS era considerado necessário para cobrir a lacuna existente no serviço de assistência aos enfermos mentais, propondo-se como instituição mais "piedosa e humana" que os outros dois hospitais (Borges, 2013). A proposta atendia a uma política nacional encabeçada pelo Serviço Nacional de Doenças Mentais (SNDM), fundado na década de 1940, que incentivou a criação de hospitais-colônia em vários estados brasileiros.

Com capacidade para funcionar com trezentos leitos, já em sua inauguração o HCS recebe os internos dos asilos de Brusque e Joinville, totalizando 311 pacientes, ou seja, onze a mais que sua capacidade máxima. Conforme o Guia dos serviços públicos e comunitários de saúde mental de Santa Catarina (1998), o HCS termina a década de 1950 com cerca de oitocentos internos, saltando, em 1967, para 1.773. No ano seguinte, a instituição aparece na lista dos hospitais psiquiátricos que utilizam os chamados "leitos-chão", camas improvisadas no chão para a internação de pacientes. Contudo, analisando os livros de registro de entrada, observa-se que, de 1942 até 1951, a instituição recebeu aproximadamente 2.300 pessoas. Conforme o Relatório do diretor do Hospital Colônia Sant'Ana (Faria, 1942), dos 309 pacientes admitidos nesse ano, 29 tinham entre 5 e 19 anos, sendo 14 homens e 15 mulheres. Os livros de registro de entrada de pacientes indicam 119 sujeitos com até 17 anos de idade somente na década de 1940. Desse total, foram localizados 86 prontuários.'

Utilizando como fontes principais um relatório de gestão, livros de registro de entrada de doentes e prontuários de jovens e crianças internados nesse hospital durante os dez primeiros anos de funcionamento, pretende-se problematizar as estratégias pelas quais a infância passou a ser pensada como alvo privilegiado de "dispositivos de segurança" no campo da psiquiatria (Prontuários..., 1940; Livros de registro..., 1941, 1942). A noção de 
"criança perigosa" e a categoria "menor" perpassam as fontes analisadas, dialogando com a discussão proposta por Foucault sobre a noção de "indivíduo perigoso". Através de uma análise genealógica, procura-se compreender de que modo os conceitos de "anormalidade" e "periculosidade" aparecem nos registros e documentos do $\mathrm{HCS}^{2}$ dando particular atenção à identificação de estratégias e ideias eugênicas dirigidas às crianças ditas "anormais" que foram enviadas ao local. Assim, a partir da leitura detalhada dos prontuários referentes ao período, foram escolhidos alguns casos, tendo como critério de seleção os que se referiam a menores ditos anormais internados no Hospital Colônia Sant'Ana na década de 1940. ${ }^{3}$

No caso da criança considerada psiquiatricamente anormal, a existência de fronteiras difusas entre normalidade e patologia psiquiátrica legitimou a ideia de que seria possível identificar pequenos signos anunciadores de uma patologia grave por vir. Isso ocorreu de dois modos. Por um lado, dizendo-se que é possível antever e evitar o nascimento de crianças anormais pela interdição dos casamentos disgênicos. Por outro, afirmando-se a possibilidade de intervenções preventivas no campo da saúde mental que permitissem agir antes do início do processo patológico.

Esses dois elementos estão presentes nos documentos, relatórios e prontuários de diversos hospitais psiquiátricos, aparecendo claramente nos arquivos analisados do HCS. O termo "anormal" é utilizado em alguns prontuários. Podem-se observar também diversos casos de crianças e jovens compulsoriamente internados pelo simples fato de apresentarem supostos comportamentos desviados que são vistos como indicadores de que uma patologia psiquiátrica poderá se desencadear no futuro.

De acordo com Foucault, para compreender de que modo surge esse contínuo médicojurídico que se articula em torno da ideia de indivíduo perigoso, é preciso se situar no período compreendido entre os anos de 1890 e 1902. A suposta periculosidade da infância, à qual este artigo especificamente se refere, caracteriza-se como uma periculosidade tanto médica quanto jurídica, que define essa figura que mais tarde levará, no Brasil, o nome de "menor". Este surge em um momento de transformação do discurso psiquiátrico e jurídico que possibilitou a articulação das categorias "criminalidade", "anormalidade" e "risco", criando um poderoso instrumento para exercer o governo sobre os homens e também sobre as condutas da infância.

No campo da psiquiatria, são abandonadas as teses defendidas pelo alienismo clássico que identificavam loucura ou doença mental a um número restrito de diagnósticos. A loucura, pela mediação dos teóricos da degeneração, deixa de estar vinculada exclusivamente à existência de alucinações auditivas ou visuais para passar a integrar comportamentos considerados desviados em relação a parâmetros preestabelecidos de normalidade. Ao mesmo tempo, afirma-se que é possível antecipar doenças psiquiátricas graves e irreversíveis que poderão ocorrer na vida adulta, o que legitima a intervenção psiquiátrica na infância e na juventude.

Sendo esses os elementos que caracterizam o discurso psiquiátrico do período, é possível observar, de acordo com Foucault (1996), que no campo jurídico ocorre uma transformação paralela. A escola positiva de antropologia criminal propõe substituir um sistema jurídico centrado na oposição responsabilidade/irresponsabilidade, vinculada ao problema do livrearbítrio, por uma legislação centrada na periculosidade. O que importa é o risco social que um 
indivíduo, adulto ou criança, pode representar para a segurança social. Assim, a noção de risco como capacidade de antecipação de um perigo possível reaparece como noção articuladora desse dispositivo de segurança que transita tanto pelo campo médico quanto pelo jurídico.

Foucault (1996) destaca ainda outras duas grandes transformações no espaço jurídico. Uma delas é a preocupação em mostrar que são justamente esses indivíduos que o direito penal clássico considerava como irresponsáveis, isto é, os loucos e anormais, que mais perigo representam para a sociedade. Surge, porém, uma pergunta inevitável: quem pode definir se um indivíduo é ou não perigoso antes de cometido o delito? Dito de outro modo: quem deve decidir se um indivíduo, seja adulto ou criança, poderá desencadear situações de violência no futuro? A resposta é a psiquiatria.

Assim, as transformações apontadas levam a uma subordinação do direito ao saber psiquiátrico, o que produzirá uma terceira transformação: o redesenhar da função social do castigo. Este deverá deixar de ser visto como punição por um crime efetivamente cometido para ser concebido como estratégia de defesa da sociedade, possibilitada pela suposta capacidade que o saber psiquiátrico teria para identificar os indivíduos perigosos. Desse modo, discurso psiquiátrico e discurso jurídico se articulam nos séculos XIX e XX, fazendo com que a saúde mental e a teoria penal transformem a figura do indivíduo perigoso no objeto principal da intervenção, tendo como alvo também a infância.

\section{A institucionalização da minoridade e suas fissuras}

A preocupação do Estado brasileiro com a institucionalização da infância e juventude perigosas e/ou abandonadas instaurou-se nessa mesma época, no final do século XIX e início do XX. Iniciativas de médicos e juristas indicavam a necessidade de criar um aparato jurídico e institucional voltado a esse segmento social. ${ }^{4}$ Salienta-se que aos médicos cabiam, prioritariamente, o combate à mortalidade infantil e o cuidado com a saúde física e mental das crianças, enquanto os juristas eram responsáveis por controlar e combater a delinquência infantil. Assim, loucura e delinquência compunham duas facetas distintas, porém articuladas, do problema da infância.

Nesse momento, o Estado multiplica intervenções tendentes a maximizar a vida, controlando acidentes, eventualidades e deficiências, e criando, para isso, uma teia de instituições de assistência (Foucault, 1997). Certamente, a criação de instituições de confinamento e assistência não é novidade. Em Santa Catarina, esse espaço específico, com características esperadas de uma instituição de saúde mental que se defina por referência ao saber psiquiátrico, então considerado científico, surge apenas em 1941, com o HCS. Essa instituição, definida como moderna, procurará instaurar mecanismos para dar conta também dos menores tidos como anormais, buscando definir o lugar a ser ocupado por eles, bem como procedimentos científicos adequados para sua regeneração. Contudo, essas práticas institucionais mostram a existência de uma série de incongruências vinculadas à definição ambígua de minoridade anormal.

As estratégias biopolíticas desenvolvidas pelo Estado a fim de regular a infância e a juventude abandonadas e/ou em conflito com a lei atendiam ao que Foucault $(1984,1997$, 2004, 2005) chamou de "biopoder", ${ }^{5}$ um poder que se encarrega da vida promovendo a 
gestão das populações, capaz de criar mecanismos de prevenção a potenciais perigos, pelo uso de um instrumental estatístico centrado na distinção entre o normal e o patológico. Entende-se por "biopolítica" um conjunto de estratégias tendentes a "fazer viver e deixar morrer", que se valem das estatísticas populacionais para legitimar a partição do espaço social em dois mundos: o dos corpos que devem ser maximizados e melhorados e o dos corpos que se transformam em alvo de políticas públicas de exclusão, confinamento e morte.

Nesse marco geral devem ser inseridas as intervenções do Estado sobre a figura da minoridade. A criação de instituições específicas para os menores anormais, ou mesmo a separação física entre crianças e adultos em instituições psiquiátricas, está presente nas discussões de médicos e juristas do final do século XIX até a primeira metade do século XX. A preocupação em "lutar pela criação de hospícios e escolas para imbecis e idiotas" aparece como um dos objetivos do Instituto de Assistência e Proteção à Infância (Ipai), criado por Moncorvo Filho no Rio de Janeiro em 1899 (Freire, Leony, 2011, p.213).

Em 1903, a criação do Pavilhão-Escola Bourneville, reservado às crianças anormais, no antigo Hospital Nacional de Alienados (HNA), no Rio de Janeiro, representou a primeira iniciativa no sentido de destinar um espaço específico para as crianças, que as separasse dos adultos. De fato, a separação de "indivíduos considerados defeituosos em espaços físicos diferentes" já ocorria no Hospício de Pedro II, no Imperial Instituto dos Meninos Cegos e no Instituto dos Surdos-mudos (Lobo, 2008, p.393). Contudo, o Bourneville procurava unir atendimento médico psiquiátrico e educação especial, surgindo como uma resposta às denúncias que, desde o final do século XIX, indicavam as péssimas condições em que viviam os menores internados no HNA.

Assim, o Pavilhão-Escola Bourneville foi a primeira instituição a realizar atendimento exclusivo a crianças tidas como anormais no Brasil, tendo como objetivo articular tratamento médico e educacional, entrelaçando discursos higiênicos e pedagógicos (Silva, 2009). O vínculo com a educação era apontado como fundamental para a regeneração, buscando-se não mais tratar a criança anormal como monstro incurável, "mas sim um indivíduo, moldável e impressionável, e por isso passível de melhora" (Silva, 2009, p.205). Desse modo, psiquiatria e educação "se constituíram nos pilares da construção de uma assistência médico-psiquiátrica infantil no início do século XX" (p.205).

A partir da década de 1930, com Vargas na presidência, a política pública voltada à saúde assume novos caminhos, pois a "política social passa a ser incorporada definitivamente como atribuição do Estado" (Fonseca, 2007, p.26). Com isso, o período que tem início nessa década pode ser caracterizado pelo crescimento da participação do Estado na assistência à infância. Apesar das preocupações e dos problemas relativos à infância serem distintos na Primeira República e no primeiro período Vargas, o papel regenerador conferido ao trabalho segue como inquietação comum. ${ }^{6}$

A questão social ligada ao pauperismo urbano foi motor de políticas públicas que dominaram o território nacional, tornando o Estado elemento central no orquestrar das ações nesse cenário. Com o Código de Menores de 1927, o menor tornou-se objeto da lei, passando a ser, ao mesmo tempo, alvo de assistência e proteção do Estado e de instâncias punitivas de exclusão, criminalização e controle. O Estado assume a função de cuidar da infância desviante, estabelecendo uma série de práticas que visam à regeneração, sobretudo 
pelo trabalho. Esse foi também um elemento articulador das "terapêuticas regeneradoras" impostas, mais tarde, aos internos do Hospital Colônia Sant'Ana, inclusive às crianças que ali eram deixadas.

A intervenção do Estado perseguia o objetivo de afastar os menores da subversão, dos maus hábitos, a fim de torná-los cidadãos úteis, sem deixar, porém, de identificar aqueles que, de algum modo, poderiam ser vistos como futuros criminosos. Essa infância desviada ou anormal opera como um verdadeiro eixo de separação entre o mundo daqueles que devem ser cuidados, cujas vidas devem ser protegidas, e o dos que carregam o estigma da periculosidade, em sentido tanto médico como jurídico, os identificados como "menores". Os discursos psiquiátrico e criminológico sustentam essa oposição.

Uma das teorias mais fortes e persistentes no campo da psiquiatria, que levou à psiquiatrização dos comportamentos cotidianos, foi, sem dúvida, a teoria da degeneração iniciada por Morel em 1857 e continuada por Magnan e Legrand em 1890. Essa teoria teve grande impacto na psiquiatria da Europa e da América Latina, promovendo a ideia de que crianças consideradas portadoras de um desvio da normalidade podiam ser identificadas por parâmetros cientificamente estabelecidos, tais como a observação de estigmas, a construção de árvores genealógicas e a identificação de comportamentos indesejados ou de heranças mórbidas.

É certo que, a partir de 1920, o termo "menor" passa a designar crianças e jovens em situação de abandono e/ou marginalidade, instituindo sua condição civil e jurídica. "Menores" seriam aqueles que necessitam de assistência, mas também de controle e de medidas de regeneração. Essa noção indica pobreza, baixa moralidade e periculosidade (Rizzini, 1997, p.23). O termo ganha assim uma conotação pejorativa, referindo-se principalmente a crianças e jovens abandonados e/ou em conflito com a lei. Há, nesse momento, duas possibilidades estabelecidas pela legislação vigente para lidar com esses menores: para as crianças abandonadas, as casas de assistência mantidas pelas irmandades leigas, ${ }^{7}$ que estavam sob a tutela do Estado; para os delinquentes, as escolas de reforma. Mas havia brechas na legislação que permitiam outros caminhos bem mais tortuosos: as penitenciárias e prisões comuns, além dos manicômios.

A Liga Brasileira de Higiene Mental (LBHM), criada em 1923, teve desde seu início essa dupla preocupação com a infância: definia os cuidados que deviam ser dedicados às crianças normais, ao mesmo tempo que propunha a identificação e a exclusão das anormais. A propagação desses novos ideais era o objetivo das palestras ministradas pelos membros da liga e de publicações, como a revista Arquivos Brasileiros de Higiene Mental. Entre os membros da LBHM, podemos citar médicos, psiquiatras e juristas, preocupados com a questão da infância e vinculados ao governo ou a instituições públicas, como Lemos Britto (advogado, jornalista e diretor da Escola 15 de Novembro entre 1926-1930), Mello Mattos (primeiro juiz da Infância e Juventude do Brasil) e Moncorvo Filho (vice-presidente da LBHM, diretor do Instituto de Proteção e Assistência à Infância, criador e diretor do Departamento da Criança no Brasil, fundado em 1919, e organizador do primeiro Congresso Brasileiro de Proteção à Infância em 1922).

A contraface dessa biopolítica que defende a criação de instituições de proteção à infância aparece de maneira evidente nos argumentos enunciados pelo fundador da LBHM, 
Renato Kehl, repetindo-se em diversos artigos publicados por prestigiosos psiquiatras, juristas e criminalistas nos Arquivos. A reverberação dessas preocupações pode ser percebida no HCS pelo material deixado por seu primeiro diretor, Agripa de Castro, que mostra a reiterada preocupação em excluir do convívio social os menores considerados desviantes, que levariam à debilitação e degeneração da raça, quando não se conseguiu evitar seu nascimento.

Assim, aparecem lado a lado estratégias biopolíticas que se confrontam entre si. Se, por um lado, existem propostas como o "consultório gratuito de psicanálise", que funcionou com regularidade até os primeiros meses de 1927, como tentativa da LBHM de atuar junto às escolas e ao Juizado de Menores, visando à correção dos menores em conflito com a lei, por outro, essas estratégias conviviam com medidas tendentes a segregar crianças e adolescentes "em estabelecimentos adequados", dirigidas a crianças tidas como "perversas irreformáveis", cuja descendência muito provavelmente estaria comprometida (Lopes, 1933). Detectar precocemente esses "menores" era uma meta a ser atingida por muitos psiquiatras e juristas que, como Lopes, estavam obcecados em evitar a propagação dos degenerados, pela reclusão dos irrecuperáveis ou pela regeneração daqueles que ainda poderiam ser reinseridos no espaço social depois de um período de reclusão.

Conforme o Código de Menores de 1927 (Brasil, 12 out. 1927), os considerados abandonados deveriam ser encaminhados a um "lugar conveniente", entregues aos pais ou ainda confiados a pessoa idônea (artigo 55). Conforme a letra b do artigo, esse local poderia ser "hospital, asilo, instituto de educação, oficina, escola de preservação ou de reforma". Em relação aos menores entre 14 e 18 anos, cúmplices ou autores de crime ou contravenção, o código previa a necessidade de "informações, a respeito do estado físico, mental e moral dele [menor], e da situação social, moral e econômica dos pais, tutor ou pessoa incumbida de sua guarda" (artigo 69).

A presença de menores na Penitenciária de Florianópolis, por exemplo, indicada por autores como Cassetari (2014), Borges (2016), Borges e Salla (2018a, 2018b), pode ser explicada se problematizarmos as "brechas" legais que remontam ao artigo 87:

Art. 87. Em falta de estabelecimentos apropriados à execução do regime criado por este Código, os menores de 14 a 18 anos sentenciados à internação em escola de reforma serão recolhidos a prisões comuns, porém, separados dos condenados maiores, e sujeitos a regime adequado; - disciplinar ou educativo, em vez de penitenciário.

Em Santa Catarina, a assistência aos menores teve início em 1935, com a criação do Juízo Privativo de Menores, órgão que passou a administrar os problemas da infância e juventude desamparada e/ou delinquente. Somente em 1940 é criado o Abrigo de Menores, que assume a missão de fornecer a formação e o cuidado a jovens e crianças do sexo masculino considerados carentes e abandonados (Arend, 2011). Seguindo a "brecha" permitida pela legislação, observa-se que, de 1930 até a criação do abrigo, os menores infratores, os ditos delinquentes, sentenciados por crimes considerados graves, eram condenados à internação na penitenciária. A separação dos sentenciados adultos, determinada pelo Código de Menores, nem sempre ocorria, e o que se observava na maioria dos casos era que os menores dividiam os mesmos espaços com os presos adultos. 
Da mesma forma que o código de 1927 autorizava a presença de menores em prisões e penitenciárias comuns, os menores tidos como anormais, de todas as idades, poderiam ser internados em hospitais psiquiátricos, também seguindo a premissa da separação entre menores e adultos, a qual na prática também nem sempre ocorria. O Código de Menores não previa um local específico para os menores abandonados e/ou em conflito com a lei que tivessem problemas mentais. O decreto n.24.559, de 3 de julho de 1934 (Brasil, 3 jul. 1934), trata da profilaxia mental e da "assistência e proteção à pessoa e aos bens dos psicopatas, a fiscalização dos serviços psiquiátricos e dá outras providências", estabelecendo que, em relação à assistência a crianças e jovens: “§ $2^{\circ}$ Os menores anormais somente poderão ser recebidos em estabelecimentos psiquiátricos a eles destinados ou em seções especiais dos demais estabelecimentos desse gênero". Vemos que existe falta de clareza em relação ao destino dado aos menores abandonados e/ou em conflito com a lei considerados com problemas mentais.

$\mathrm{Na}$ análise da documentação institucional do período estudado, principalmente os prontuários dos menores internados no HCS na década de 1940, é possível observar que não existia uma clara separação entre internos menores e adultos. Somente em 1985 tem-se uma tentativa de promover essa separação por intermédio da criação de uma unidade infantil (Unifanto), extinta poucos anos depois (Fontoura, 1997). O livro de registro de pacientes do HCS mostra que havia um número expressivo de menores de 17 anos internados, chegando a contabilizar 119 jovens e crianças em dez anos (1941-1952), sem que exista referência a um local especificamente destinado a eles, separado do espaço dos adultos.

Na década de 1940, tem-se a criação de uma rede de organismos cujo objetivo era a regulação das instituições públicas e privadas que realizavam serviços na área da infância desvalida, por meio do Departamento Nacional da Criança (1940) e do Serviço de Assistência a Menores (1941). O primeiro visava instaurar ações voltadas à maternidade e à infância por meio de políticas de combate à mortalidade infantil, amparo e educação das mães, divulgação de preceitos morais e higiênicos. Ao segundo cabia implementar uma política centralizadora que buscava, via ações educacionais, médicas e psicológicas, garantir a redução dos problemas ligados aos menores desvalidos e, fundamentalmente, a jovens delinquentes.

Existem poucos trabalhos dedicados a analisar os efeitos dessa política pública em Santa Catarina, onde a constituição e a implementação de políticas de assistência e controle dos menores são caracterizadas pela inexistência de recursos financeiros regulares e pela tardia criação de instituições, já em funcionamento em outros estados (Pereira, 2006). Há também poucas fontes documentais disponíveis. Por esse motivo, muitas áreas permanecem ainda inexploradas em relação ao tema da infância anormal nesse estado. Este estudo assume o desafio de apresentar uma primeira análise de uma documentação pouco investigada, sem pretender esgotar todas as possibilidades, procurando delinear algumas pistas que permitam abrir uma agenda de pesquisa futura que se debruce, a partir de diversos pontos de vista, sobre esses documentos.

A presença de menores no HCS vem sendo observada nos dados levantados pela organização do Centro de Documentação e Pesquisa do Hospital Colônia Sant'Ana (Cedope/ HCS). ${ }^{8}$ Um dos primeiros resultados desse levantamento é o trabalho de Bruna Viana (2015), 
que analisou aspectos da assistência psiquiátrica a crianças e jovens no estado de Santa Catarina. O referido estudo permite observar a existência de crianças e jovens internados sem local reservado, ocupando o mesmo espaço que os adultos.

Ainda que vários autores (Alvarez, 1989; Rizzini, 2000) já tenham analisado o significado do Código de Menores de 1927 e seus efeitos, cabe aqui discutir as fissuras que permitiram desvios na proposta de gestão da minoridade, principalmente no que tange aos ditos anormais. Esse código trabalhava com várias categorias: abandonado, pervertido, vicioso, libertino, delinquente e débil (Borges, Salla, 2016). É principalmente sobre a última categoria, a dos débeis, que se concentra a análise.

\section{Menores anormais: degeneração e eugenia}

Como já mencionado, a noção de "criança anormal" teve, no Brasil, uma forte influência da teoria da degeneração de Morel, partindo da ideia de um desvio da normalidade esperada para essa faixa etária. As crianças anormais eram consideradas inferiores, um defeito ou desvio social que não condizia com o ideal de nação proposto pelo governo Vargas. ${ }^{9}$ Nessa época, conforme Lilia Schwarcz (1993), no Rio de Janeiro, médicos embasados na perspectiva eugênica e higienista propuseram a esterilização de grupos tidos como anormais, impedindo assim sua procriação, proposta que reaparece no contexto de Santa Catarina no relatório de Agripa de Castro sobre o HCS.

Recordemos que, para Foucault (1999, p.298), "a degeneração é a peça teórica maior que permite a medicalização do anormal. O degenerado é o anormal miticamente - ou, se vocês preferirem, cientificamente - medicalizado". ${ }^{10}$ Foucault situa o início desse processo no Tratado de degeneração física, moral e mental, publicado em 1857, por Benedict Morel (1857, p.75), que define o princípio geral da teoria da degeneração do seguinte modo: "Os seres degenerados formam grupos e famílias com elementos distintivos relacionados invariavelmente às causas que lhes transformaram nisso que eles são: um desvio mórbido do tipo normal da humanidade".

Por outro lado, nas primeiras décadas do século XX, a eugenia aparece como tema recorrente em publicações médicas e científicas em diferentes países do mundo. Uma referência obrigatória sobre as peculiaridades da eugenia na América Latina é o livro de Nancy Stepan (2005) A hora da eugenia: raça, gênero e nação na América Latina, onde são analisados os casos de Brasil, Argentina e México. No caso específico da eugenia brasileira, diferentes estudos se dedicaram às controvérsias ocorridas nas décadas de 1920 e 1930, relacionadas às estratégias a serem adotadas para garantir uma população considerada apta. No que se refere à psiquiatria brasileira, Vanderlei de Souza (2006a, 2006b, 2006c, 2016) analisa o surgimento de importantes controvérsias entre autores que, como Renato Kehl, defendiam a eugenia e a esterilização negativas dos doentes mentais e degenerados, e os que defendiam uma eugenia preventiva (Stepan, 2005) e se negavam a aceitar essas medidas consideradas radicais, como é o caso de Roquette-Pinto (Souza, 2016, p.93).

Nessa época, a eugenia também aparece como tema recorrente em publicações médicas e científicas, como os Arquivos Brasileiros de Higiene Mental, a Gazeta Médica de Bahia, os Arquivos Brasileiros de Neuriatria e Psiquiatria, o Boletim de Eugenia do Instituto Brasileiro da 
Eugenia (edições de 1929, 1930 e 1931). Em 1929, é realizado o primeiro Congresso Brasileiro de Eugenia, presidido por Renato Kehl, que nesse ano publica seu livro Lições de eugenia, em que defende a tese da "esterilização eugênica dos degenerados", dando continuidade ao texto publicado em 1925, "A esterilização dos grandes degenerados e criminais" (Kehl, 1929). Renato Kehl também defendeu estratégias de eugenia preventiva, de tal modo que seja possível propagar traços ótimos por via da herança e, ao mesmo tempo, eliminar os indesejáveis (Stepan, 2005). Porém, para Robert Wegner e Vanderlei de Souza (2012), ao longo de sua carreira, Kehl adota uma posição cada vez mais cética em relação à eugenia preventiva.

Embora existam diferenças significativas entre os discursos dos degeneracionistas e dos eugenistas, é possível afirmar que a teoria da degeneração já tinha criado, no campo da psiquiatria, um dispositivo biopolítico que permitiu legitimar e tornar aceitáveis as intervenções propostas pelos eugenistas. Ambos os grupos compartilhavam um mesmo ponto de partida: o mito da normalidade hereditária e da herança mórbida, e estavam preocupados em identificar uma série de características físicas e comportamentais consideradas indesejáveis, os estigmas, como indicadores de desvio da normalidade. 0 discurso inaugurado pelos degeneracionistas, referente à degradação progressiva dos heredodegenerados, parece servir como justificativa, no campo da saúde mental, para as intervenções eugênicas propostas nas últimas décadas do século XIX por Frances Galton (1889). Assim, no início do século XX, a psiquiatria começa a se transformar num discurso que aceita como naturalmente dadas as estratégias eugênicas. Talvez essa aceitação possa ser entendida pelo fato de a teoria da degeneração ter deixado um marco explicativo para as patologias mentais, baseado nos estigmas, árvores genealógicas e hereditariedade mórbida, que criou as condições de possibilidade para a aceitação e integração do discurso eugênico. O certo é que diversos psiquiatras do início do século XX defenderam a implantação de intervenções eugênicas destinadas a limitar a proliferação de sujeitos anormais.

Emil Kraepelin (2007, p.400), por exemplo, considerado o fundador da psiquiatria moderna, defende que as estratégias de amparo social aos indivíduos vulneráveis representam um obstáculo para a purificação eugênica da raça, afirmando:

Em todo caso, é impossível saber quantos idiotas, epiléticos, psicopatas, criminosos, meretrizes e vagabundos são filhos de pais alcoólicos ou sifilíticos e herdaram a inferioridade de seus pais. É óbvio que o dano será em parte compensado por sua menor capacidade para sobreviver. Mas, infelizmente, a extensão de nossos programas de assistência social tem o efeito de impedir a autopurificação natural de nosso povo.

Esse discurso se repete incansavelmente na psiquiatria e na medicina brasileiras de inícios do século XX, em particular no caso dos membros da Liga de Higiene Mental, reaparecendo, por exemplo, vinte anos depois da afirmação de Kraepelin, no texto de Renato Kehl (1929, p.93):

Evidencia-se por toda parte a preocupação dos governos por encontrar soluções para abrigar e alimentar a uma elevada percentagem de incapazes, criminais e anormais. Para agravar a calamitosa situação, higiene, medicina e filantropia salvam a vida de milhões desses infra-homens (que a seleção natural deveria eliminar), aumentando assim as contribuições para mantê-los em inatividade ou encerrados em instituições. 
Para evitar o nascimento dos anormais ou intervir quando eles já nasceram, era necessário contar com estratégias que permitissem sua identificação. As estratégias privilegiadas eram duas: a procura de estigmas e a construção de árvores genealógicas. Em relação à primeira, no Brasil, diversos psiquiatras e eugenistas realizaram uma minuciosa descrição de estigmas: a simetria ou deformação da cabeça, do rosto, dos membros; os vícios de conformação das orelhas; o retardo intelectual e mental; o cretinismo; o alcoolismo. Todas essas características representavam estigmas que condenariam à degeneração os descendentes (Souza, 2013, p.161).

Por outro lado, as árvores genealógicas permitiam legitimar estratégias eugênicas, como a esterilização dos heredodegenerados ou a limitação de casamentos disgênicos. Para Kehl (1929), as árvores genealógicas (pedigree) eram consideradas indispensáveis para avaliar a força hereditária dos cônjuges.

Poucos anos mais tarde, em 1933, um conhecido eugenista chamado Ernani Lopes publica nos Arquivos de Higiene Mental o artigo "Alta tardia aos heredopsicopatas por motivo de ordem eugênica". Ainda que a proposta não tenha sido colocada em prática, era considerada como um dos meios para garantir o progresso do país. Assim, para Renato Kehl:

É preciso evitar a proliferação desses doentes, incapazes e loucos ..., a esterilização fará desaparecer os elementos cacoplatos da espécie humana, ou melhor, a sua proporção será reduzida, mas não se garante a perfeição, só conseguida com um processo eugênico (citado em Schwarcz, 1993, p.234).

Muitas das estratégias biopolíticas aqui analisadas estão presentes nos documentos que retratam os primeiros anos do HCS, tais como a preocupação com genealogias, a construção de árvores genealógicas para cada paciente, a identificação de estigmas e a ideia de que é necessário intervir para garantir a interdição da reprodução dos anormais. Contudo, cabe destacar que tanto Pinel (2007), em seu Tratado médico-filosófico a respeito da alienação, quanto Kraepelin, em seu minucioso trabalho de classificação das doenças mentais, não destacaram as especificidades das doenças psiquiátricas em crianças. No entanto, é possível perceber as reverberações do pensamento psiquiátrico da época no que tange aos menores anormais aqui analisados.

\section{Menores anormais no Hospital Colônia Sant'Ana}

A associação entre a teoria da degeneração e práticas eugênicas reaparece em 1942 no relatório do Serviço de Assistência a Psicopatas do HCS. Segundo esse documento, o hospital integrava entre suas tarefas "o estudo e a prática dos meios gerais e especiais destinados a impedir o nascimento de seres psiquicamente anormais ... apoiados no conhecimento do caráter hereditário das doenças mentais" (Faria, 1942, p.7-8). O relatório destaca duas tarefas centrais da instituição: (1) assistir os doentes mentais e (2) evitar que os seres que vão nascer e os já nascidos se transformem em doentes mentais. Para cumprir este último objetivo, diz o documento: "Só se evita que um novo ser seja um doente mental evitando a procriação daqueles que têm doentes mentais em sua árvore genealógica" (s.p.). Por fim, à pergunta "existem dados científicos que mostrem que a 
loucura se transmite hereditariamente?", o relatório responde: "Sim. Proíba-se o casamento dos anormais" (s.p.).

Tais questões fazem parte de uma política de higiene mental preocupada com aspectos ligados à hereditariedade e suas interfaces com os meios sociais. Assim, quando se analisa o relatório apresentado por Agripa de Castro Faria em 1942, é com perplexidade que se constata a permanência dos velhos mitos da hereditariedade mórbida vinculados à teoria da degeneração. Vê-se que a ideia de uma profilaxia moral por antecipação e prevenção de riscos, centrada em aspectos ligados à higiene mental, abre as portas para a aceitação de medidas eugênicas, tais como: o exame pré-nupcial; a interdição do casamento aos doentes, alcoólatras e anormais em geral; a tentativa de estabelecer as genealogias dos pacientes, demonstrada pela necessidade de começar a construção de árvores genealógicas que, segundo Agripa, estão ausentes na instituição; a procura por estigmas e marcas de degeneração.

Podem-se observar afirmações como esta:

É imprescindível que saiamos deste marasmo para que possamos fechar o círculo de atividades da higiene e profilaxia mentais, procurando dar amparo às ideias modernas sobre o assunto, quais sejam, as baseadas nos conhecimentos sobre os problemas de hereditariedade das doenças mentais (Faria, 1942, s.p.).

A primeira das medidas propostas para sair do círculo vicioso que leva ao aumento das doenças mentais é a instituição do exame pré-nupcial. Porém, para que essa medida seja eficaz, é necessário conhecer não só as manifestações evidentes no fenótipo, mas a realidade oculta, aquela que se transmite pelo sangue de maneira hereditária, o genótipo. Aquilo que em tempos de Magnan (1887) se denominava simplesmente "hereditariedade mórbida" reaparece com uma retórica mendeliana. Porém, o temor a uma herança patológica difusa, a herança dissimilar, permanece inalterado. Para Agripa de Castro, essa medida está condenada ao insucesso, perante a total ausência de "inquéritos genealógicos". Repete-se, assim, a clássica ideia de corpo ampliado do doente mental, analisada por Foucault (2003) em $O$ poder psiquiátrico. Perante a impossibilidade de localizar no corpo, particularmente no cérebro, uma explicação para as patologias mentais, a psiquiatria recorrerá ao conjunto ambíguo de patologias familiares, que constitui o corpo ampliado.

É nessa perspectiva que se deve entender a afirmação que aparece reiteradas vezes no relatório: "Só se evita que o novo ser seja um doente mental impedindo a procriação de seres doentes que tenham doentes em sua árvore genealógica" (Faria, 1942, s.p.). Ainda que o exame nupcial não tenha entrado no Código Penal de 1940, aparece disseminado nos discursos de juristas e psiquiatras da época, bem como nas instituições de abrigamento e na organização cotidiana destas. No caso do HCS, observando-se detidamente essa afirmação, é possível ver que não se trata de evitar apenas a propagação de doentes mentais, mas de "doentes" em sentido amplo. As ideias de hereditariedade mórbida e herança dissimilar reaparecem ainda quando se faz referência a genótipos. Como dirá Foucault, trata-se de saber se existe na família qualquer tipo de doença, não importa se é um pai alcoólatra, uma mãe tuberculosa ou um primo idiota, de todo modo fica legitimada a interdição dos matrimônios. 
Assim, Agripa de Castro fala de hereditariedade recessiva e da força das evidências que mostram a hereditariedade das patologias mentais. Ele diz que é difícil achar um doente mental sem que exista pelo menos um suicida na árvore genealógica. Em definitivo, tudo leva a afirmar que a única medida verdadeiramente eficaz é a interdição do matrimônio dos seres anormais. E mais ainda: Agripa afirma que "Todos os outros meios são indisfarçavelmente ineficazes e não eugênicos" (Faria, 1942, s.p.).

Por isso, não é possível deixar de observar o perfil eugênico do relatório: vez ou outra aparece considerada como a medida mais eficaz a interdição dos matrimônios disgênicos, e a definição de anormalidades e patologias que devem ser declaradas é quase ilimitada. Trata-se de uma proposta que não se resume ao espaço concreto e restrito do HCS. A proposta é criar na cidade de Florianópolis, com apoio do governo, um atendimento ambulatorial de higiene mental, o que de fato significa um controle da psiquiatria sobre o conjunto do espaço social, em particular dos indivíduos considerados perigosos, com fins preventivos. A psiquiatria, segundo é possível ler no relatório, não deve limitar-se à terapêutica; pelo contrário, espera-se dela que seja essencialmente profilática.

Assim, além da criação e registro de árvores genealógicas das famílias dos internos, primeira das tarefas propostas, o Serviço de Higiene Mental tem a missão de: controle de epidemias; campanha sobre a vida mental das crianças; campanha nas escolas; campanha de esclarecimento sobre a necessidade do exame pré-nupcial; controle da literatura destinada às crianças; campanha contra álcool, cocaína e morfina; controle dos egressos das penitenciárias e hospitais psiquiátricos; controle sobre oligofrênicos perfectíveis. A tudo isso se acrescentará o controle dos desocupados, afirmando-se que "os desocupados são, em geral, doentes mentais" (Faria, 1942, p.12). A proposta é apresentar um trabalho geral, intra- e extra-asilar, ou, como afirma Agripa de Castro Faria (p.13): “Uma visão de conjunto sobre o problema no Estado vem pedir uma orientação segura para a prática de medidas eugênicas que serão adotadas em breve no Brasil".

Mas resta saber o que pode ser feito antes que essas medidas eugênicas sejam implementadas, ou, nas palavras do relator: "Como evitar que aqueles já nascidos se tornem doentes mentais?". Isso se fará acompanhando, corrigindo, disciplinando as crianças que tenham ainda capacidade de recuperação. O foco deverá estar posto na infância, pois se trata de "acompanhar o desenvolvimento mental das crianças em todas as idades, corrigindo as tendências instintivas filhas do genótipo" (Faria, 1942, p.9). Mais uma vez aparece o temor a uma herança mórbida indefinida, que se apresenta aqui sob a retórica do genótipo.

Nessa perspectiva, os diagnósticos, nem sempre indicados, estão ligados fundamentalmente a classificações relacionadas a déficit de inteligência e padrões de desenvolvimento. Conforme Viana (2015, p.73), entre os diagnósticos apontados nos menores, destacam-se, por ordem de incidência:

encefalopatia infantil; epilepsia; idiotia; esquizofrenia; oligofrenia; psicose maníacodepressiva e imbecilidade. Além desses, chama atenção o grande número de pacientes que não obtiveram nenhum tipo de diagnóstico, ou seja, nenhuma identificação enquanto anormais ou doentes, que justificasse sua permanência na instituição. 
Em muitos casos, ao menor poderiam ser atribuídas patologias diferentes durante o internamento, como J. (Prontuário 73), que recebeu três diagnósticos diferentes entre 1942, ano de sua entrada, e 1949, quando veio a óbito: encefalopatia infantil, oligofrenia e imbecilidade. Nos prontuários analisados, é possível perceber a preocupação em registrar informações como os antecedentes hereditários dos menores, aspectos ligados a seu passado familiar e suas potencialidades para o trabalho. Observações como: "irmãos psicopatas internados na mesma colônia" (Prontuário 791, 1946), "pai alcoólatra" (Prontuário 180, 1943), "irmã doente mental internada na Colônia" (Prontuário 1.193, 1947), "um tio e o avô do paciente sofrem de ataques" (Prontuário 461, 1944) etc. No relatório de 1942, é mencionada a necessidade de se criar um ambulatório de higiene mental, visando a uma ampla campanha que atuaria de forma direta junto às famílias.

A implementação de Ambulatórios de Higiene Mental (AHM) nos estados correspondia às campanhas de prevenção às doenças mentais, empreendidas na década de 1940 pelo SNDM, as quais tinham como objetivo promover os preceitos da higiene mental por meio de ações intervencionistas de caráter assistencialista. Agripa de Castro Faria (1942, s.p.) considerava o Ambulatório de Higiene Mental "o pivô da profilaxia mental, e sua falta é lacuna grande no nosso serviço". Santa Catarina, a exemplo de outros estados, teve seu ambulatório criado na década de 1960; contudo, o psiquiatra indicava a necessidade dessa instituição já em 1942.1" O ambulatório teria função preventiva, interferindo diretamente na gestão das famílias e no levantamento e sistematização de dados, os quais atenderiam a uma "campanha sabiamente orientada", preparando "o terreno para a execução de uma obra eugênica" (Faria, 1942, s.p.).

Algumas indicações apontadas como funções do futuro ambulatório aparecem já colocadas em prática no HCS na década de 1940: "Manter um serviço de contato permanente entre o doente e sua família; Levantamento de dados genealógicos das famílias dos doentes internados em um sistema de ficha moderna" (Faria, 1942, s.p.). Essa preocupação fica evidente nos prontuários dos menores, sendo possível observar a implantação do que o diretor chama de sistema "moderno" de fichas de informação, que possibilitariam o "levantamento de dados genealógicos das famílias dos doentes internados" (s.p.). Essa ficha não está presente em todos os prontuários, e em muitos casos os campos não são inteiramente preenchidos. O campo referente aos "antecedentes hereditários", que demonstra a preocupação com a maneira como a doença teria se manifestado na família, dependia de informações solicitadas aos familiares, pois o paciente nem sempre conseguia informar dados relevantes, sendo frequente nos prontuários a observação "doente incapaz de prestar qualquer informação".

A preocupação em entender como a doença se manifestou pela primeira vez no paciente aparece em uma carta anexada ao prontuário de M. (Prontuário 1.110), na qual a família responde ao psiquiatra:

Hoje recebemos a sua carta pedindo informações da doença da M. É o seguinte, começou a moléstia, de repente deu uma febre muito forte isso foi de manhã, e à noite deu um ataque, e o médico não atestou a qualidade de ataque que era. No dia seguinte arrebentou umas bolhas e deu uma disenteria forte e levou quase um mês doente aí sarou, mas ficou muito nervosa, não comia com as mãos dela e ficou com uma perna 
mais curta do que a outra. Isso foi com a idade de 2 anos, e depois foi crescendo e foi agarrando uma cisma que estavam jogando areia nela. Com a idade de 13 anos ela deparou-se moça, mas ela não sabe o que era, ela diz que machucaram e diversas coisas, e até a data de hoje, ela não se trata de um nada, e tem muita vergonha de comer na frente dos estranhos, e quando ela cisma rasga a roupa, xinga e diz muitos nomes feios na frente de qualquer pessoa, tem noite que ela dorme bem e tem noite que ela cisma vai até meia-noite, e a gente tem que fazer todas as vontades, se não ela fica mais ruim, ocasião de lua e perto dos incômodos ela fica bem ruim. Quando ela se acha doente ela não conta nós temos que adivinhar. ${ }^{12}$

A carta, assinada pelo pai de M., é marcada por apreciações que misturam sintomas orgânicos, físicos e psicológicos iniciados aos 2 anos de idade e que perduraram até sua internação no HCS, aos 16 anos. O pai faz referência às ocasiões de "lua" e perto dos "incômodos", apontando o ciclo menstrual como responsável pelos períodos de crise. Cabe salientar que um dos formulários anexados ao prontuário destinava-se ao controle do ciclo menstrual das internas. Seu preenchimento é raro, e, quando ocorre, é de forma esparsa.

De modo geral, os registros dos prontuários analisados não são sistemáticos. Em alguns casos ocorrem em intervalos de meses e até anos. A observação "adapta-se ao trabalho" é uma constante, sempre acompanhada de indicação à praxiterapia. O prontuário de $\mathrm{A}$. (Prontuário 62), de 17 anos, internada em 1942 com o diagnóstico "oligofrenia/débil mental", é exemplar nesse sentido:

17/04/48 - Paciente continua no mesmo estado mental como quando entrou no hospital. $O$ estado mental permanece inalterado.

1949 - Mesmo estado mental inalterado.

21/09/1949 - Não tem modificação o estado mental. Recomenda-se a praxiterapia na lavanderia.

25/05/1950 - Submete-se bem ao trabalho. Conduta não modificou em nada. Nível mental baixo.

Atividades como "cozinha" e "lavanderia" eram frequentemente recomendadas às meninas; já para os meninos a atividade principal era na lavoura. Apesar de pregar-se a necessidade de instrução e educação para os "pequenos anormais", "eternos desadaptados ao meio" (Faria, 1942, s.p.), essa prática não ocorria no HCS. A indicação do trabalho como recurso terapêutico sempre foi uma constante nos hospitais psiquiátricos. No século $X X$, estar apto ao trabalho passa a ser condição para que o interno possa retornar ao meio social. Agripa Faria (1942, s.p.) salienta a necessidade de construção de oficinas, como "colchoaria, cestos, vassouras, tamancos, esteiras" etc., que possibilitem empregar o trabalho dos pacientes, os quais eram "utilizados quase que só atualmente na lavoura", ampliando assim as possibilidades da praxiterapia.

A proeminência da praxiterapia atendia às políticas públicas implantadas pelo SNDM, cuja campanha deflagrada na década de 1940 indicava que "na nova sociedade brasileira era preciso que o doente mental tivesse assistência digna, em lugar isolado, tendo a praxiterapia como principal forma de tratamento" (Botti, 2004, p.29). A exemplo do que ocorria em outras instituições, como a Colônia Juliano Moreira, maior colônia agrícola do Brasil, localizada no Rio de Janeiro, a base terapêutica deveria estar fundamentada na 
praxiterapia e na assistência heterofamiliar (Venancio, 2011). A implantação da assistência heterofamiliar é apontada no relatório (Faria, 1942, s.p.).

Para fiel cumprimento de uma terapêutica eficiente, é necessário salientar a execução de um programa de construção para a assistência heterofamiliar, residências colocadas longe das outras e que servissem para moradia de funcionários e para onde fossem os doentes com alta, como ponto de passagem do meio hospitalar ao meio social.

O serviço de assistência heterofamiliar foi implantado somente na década de 1950 no HCS (Santaella, 1951). Contudo, a preocupação em apontar a necessidade desse serviço em 1941 demonstra uma tentativa de atender às políticas de saúde mental do período.

No prontuário de A. aparece outro aspecto recorrente também nos registros de outros internos. Nas anotações anuais de 1948 a 1952, constata-se sempre a mesma observação lacunar sobre a doente: "mesmo estado mental". Essa observação mostra um acompanhamento marcado pelo registro superficial e sem detalhes, instituindo uma regularidade que permitia uma internação sem prazo definido, que em muitos casos persistia até o óbito.

Dos 86 casos analisados, em 49 consta "alta" como "motivo da saída", em nove prontuários não existe nenhum registro e em 28 é indicado óbito. Nestes, a causa da morte raramente é indicada, não sendo possível encontrar nenhum atestado de óbito. No prontuário de M.J.S. (Prontuário 378), consta um telegrama datado de 16 de fevereiro de 1948, assinado pelo doutor Agripa Faria, informando a família: "Comunico que M.J.S. faleceu dia 14 corrente". O menor tinha 11 anos de idade quando foi internado no HCS, em 1943. Seu prontuário é lacunar, com poucas informações, descrevendo-o basicamente como de "fisionomia sonolenta" e destacando que "não responde ao interrogatório". A causa de sua morte não é informada no prontuário, tampouco no telegrama enviado à família pela direção.

A ausência de informações sobre os óbitos e a maneira lacunar com que eram comunicados às famílias aparece em outros prontuários. O de M.R. (Prontuário 1.169), internado em 1948 com 15 anos de idade, contém telegramas assinados pela mãe solicitando informações sobre o filho. "Peço notícias do interno M.R.", diz o último deles, datado de 10 de fevereiro de 1956. A resposta era sempre a mesma: "passando bem". Por fim, nesse mesmo ano e apenas três meses após a mãe ser informada que o filho passava bem, um novo telegrama endereçado a ela, datado de 12 de maio de 1956, relatava: "Comunico falecimento de M.R. ocorrido hoje. Ass: Diretor da Colônia".

\section{Considerações finais}

O presente artigo buscou contribuir com uma questão ainda pouco estudada e extremamente inquietante: os caminhos da assistência psiquiátrica dedicada a crianças e jovens ditos anormais em Santa Catarina. Para trilhar esse percurso, a proposta partiu da problematização da noção de criança anormal. Procurou-se demonstrar como tal categoria, surgida nas últimas décadas do século XIX e início do XX, articula-se em torno das noções de criança psiquiatricamente anormal e criança delinquente ou perigosa. 
É possível vislumbrar a capilaridade dessas categorias nos documentos referentes aos menores tidos como anormais enviados ao Hospital Colônia Sant'Ana na década de 1940. Percebe-se nesses registros a permanência dos velhos mitos da hereditariedade mórbida vinculados à teoria da degeneração, nos quais a tênue fronteira entre normalidade e patologia psiquiátrica corroborou a perspectiva de que seria possível apontar pequenos signos indicadores de prováveis patologias graves futuras. As estratégias biopolíticas desveladas a partir da análise dos primeiros anos de funcionamento do antigo HCS mostram a preocupação com genealogias, a construção de árvores genealógicas para cada paciente, a identificação de estigmas e a noção de que é preciso intervir para assegurar a interdição da reprodução dos ditos anormais.

As fontes apontam ideias imbuídas de uma perspectiva eugênica, indicando a necessidade de controle e intervenções preventivas, como interdição de casamentos disgênicos e interferências no sentido de agir antes que o quadro patológico seja iniciado. Contudo, observou-se a inexistência de diagnósticos que apontassem patologias psiquiátricas claramente definidas. O internamento ocorria sobretudo em função de supostos comportamentos desviantes, entendidos como indicadores de supostas patologias psiquiátricas que poderiam se desencadear no futuro.

Nesses registros é possível ainda encontrar dados ligados a antecedentes hereditários, bem como a aspectos do passado familiar dos internos. Esse conjunto de informações elencadas pelas fontes institucionais faz parte das inquietações de uma política de higiene mental preocupada com aspectos ligados à hereditariedade e suas interfaces com os meios sociais.

Por meio da análise de documentos encontrados no arquivo do antigo Hospital Colônia Sant'Ana, observou-se a atualidade de antigas estratégias de controle do século XIX, ainda reverberando na psiquiatria catarinense da primeira metade do século XX. A tessitura da trama institucional possibilitou problematizar os vínculos existentes entre as ideias eugênicas e as teorias que permitem identificar as crianças ditas anormais.

\section{AGRADECIMENTO}

O presente artigo faz parte da pesquisa "Tempo presente e instituições de isolamento social em Santa Catarina: perscrutando histórias marginais", desenvolvida de 2014 a 2017 com recursos financeiros do Conselho Nacional de Desenvolvimento Científico e Tecnológico (CNPq) do Ministério da Ciência e Tecnologia (n.443433/2014-3).

\section{NOTAS}

\footnotetext{
1 Tais fontes também foram consultadas por Bruna Viana (2015), que, do mesmo modo que o levantamento aqui apresentado, deparou-se com questões como ausência de prontuários ou incoerências nos registros (que apresentam, por exemplo, alterações nas idades dos pacientes) para além do período estudado neste artigo.

2 A proposta genealógica foucaultiana visa expor a "proveniência" de saberes e práticas e como as contingências formatam o presente (Garland, 2009), entendendo que as coisas não possuem uma essência a ser desvelada (Foucault, 2012).

${ }^{3}$ Tentamos abranger toda a década de 1940, mas cabe salientar as dificuldades encontradas nessa empreitada, visto que os prontuários desse período são fontes lacunares, pois nem sempre foram preenchidos de forma clara. Dados gerais como nome, procedência, profissão, quando preenchidos, puderam ser detectados
} 
de forma mais evidente. O mesmo não ocorreu com os diagnósticos, muitas vezes registrados de forma indecifrável ao longo do documento, e também quanto a observações dispersas sobre as origens da doença e a vida pregressa do internado. Assim, os casos elencados no presente artigo, além de expressarem como operava a dinâmica institucional que envolvia os menores ditos anormais, foram aqueles possíveis de serem pesquisados em detalhes. Ver: Prontuários... (1940). A respeito das dificuldades da pesquisa com prontuários, ver Salla e Borges (2017).

${ }^{4}$ A respeito da história da infância e adolescência, ver: Vianna (1999), Arend (2011), Alvarez (1989).

${ }^{5}$ A esse respeito, ver Foucault $(1978,1979,1984,1997,2004,2005)$.

${ }^{6}$ A respeito da infância desvalida em Florianópolis e das mudanças nas políticas a ela destinadas da Primeira República ao governo Vargas, ver Pereira (2006).

${ }^{7}$ No caso do HCS, trata-se da Irmandade da Divina Providência.

${ }^{8}$ A organização do acervo do HCS vem sendo empreendida por meio do Projeto de Extensão Arquivos Marginais, coordenado pela professora Viviane Borges, da Universidade do Estado de Santa Catarina, tendo como colaboradora a professora Sandra Caponi, da Universidade Federal de Santa Catarina. A esse respeito, ver Borges (2016).

${ }^{9}$ A respeito da saúde das crianças no governo Vargas, ver Fonseca $(1990,1993)$.

${ }^{10}$ Nesta e nas demais citações de textos em outros idiomas, a tradução é livre.

11 Os ambulatórios foram criados apenas na década de 1960. Braga (2012) aponta a existência de 23 ambulatórios em diferentes localidades espalhadas pelo Brasil: Manaus, São Luís, Teresina, Fortaleza, Natal, João Pessoa, Campina Grande, Maceió, Aracaju, Salvador, Vitória, Niterói, Rio de Janeiro, São Paulo, Belo Horizonte, Curitiba, Florianópolis, Porto Alegre, Pelotas, Goiânia, Cuiabá. Além desses, estavam aguardando abertura os de Belém, Recife e Olinda.

${ }^{12}$ Grafia atualizada, pontuação de acordo com o original.

\section{REFERÊNCIAS}

ALVAREZ, Marcos.

A emergência do Código de Menores de 1927: uma análise do discurso jurídico e institucional da assistência e proteção aos menores. Dissertação (Mestrado em Sociologia) - Universidade de São Paulo, São Paulo. 1989.

AREND, Sílvia.

Histórias de abandono: infância e justiça no Brasil (década de 1930). Florianópolis: Editora Mulheres. 2011.

BORGES, Viviane Trindade.

Abandonados e pervertidos, ou em perigo de o ser: biopoder e práticas de normalização dos menores enviados à Penitenciária de Florianópolis (SC, década de 1930). Trashumante: Revista Americana de Historia Social, v.8, p.176-199. 2016.

BORGES, Viviane.

Um "depósito de gente": as marcas do sofrimento e as transformações no antigo Hospital Colônia Sant'Ana e na assistência psiquiátrica em Santa Catarina, 1970-1996. Revista História, Ciências, Saúde - Manguinhos, v.20, n.4, p.1.531-1.549. 2013.

BORGES, Viviane Trindade; SALLA, Fernando. Aspectos da gestão da menoridade em Florianópolis e São Paulo, 1930-1940. História Unisinos, v.22, n.1, p.100-110. 2018a.
BORGES, Viviane Trindade; SALLA, Fernando. A gestão da menoridade sob o Serviço Social de Assistência e Proteção aos Menores de São Paulo, 1930-1940: encruzilhada de saberes. Saúde e Sociedade, v.27, n.2, p.326-337. 2018b.

BORGES, Viviane T.; SALLA, Fernando. A construção do saber criminológico sobre os menores abandonados, delinquentes, pervertidos nas décadas de 1930 e 1940. In: Seminário Nacional de História da Ciência e da Tecnologia, 15., 2016, Florianópolis. Anais eletrônicos... Florianópolis: Sociedade Brasileira de História da Ciência. Disponível em: <http://www.15snhct.sbhc.org. br/resources/anais/12/1473450770 ARQUIVO_15ENSBHCPaper-2.pdf >. Acesso em: 6 fev. 2018. 2016.

BOTTI, Nadja Cristiane L.

Oficinas em saúde mental: história e função. Tese (Doutorado em Enfermagem Psiquiátrica) Universidade de São Paulo, São Paulo. 2004.

BRAGA, André.

O Serviço Nacional de Doenças Mentais no governo JK: a assistência psiquiátrica para o Distrito Federal. In: Encontro Regional de História da Anpuh-Rio, 15., 2012, Rio de Janeiro. Anais... Rio de Janeiro: Associação 
Nacional de História-Rio. Disponível em: $<$ http://www.encontro2012.rj.anpuh.org/ resources/anais/15/1338477418_ARQUIVO_ TextocompletoparaaANPUH2012.pdf $>$. Acesso em: 6 fev. 2018. 2012.

BRASIL.

Poder Executivo. Decreto n.24.559, de 3 de julho de 1934. Dispõe sobre a profilaxia mental, a assistência e proteção a pessoa e aos bens dos psicopatas, a fiscalização dos serviços psiquiátricos e dá outras providências. Coleção de leis do Brasil. Disponível em: <http://www2. camara.leg.br/legin/fed/decret/1930-1939/ decreto-24559-3-julho-1934-515889publicacaooriginal-1-pe.html>. Acesso em: 10 out. 2018. 3 jul. 1934.

BRASIL.

Poder Executivo. Decreto n.17.943-A, de 12 de outubro de 1927. Consolida as leis de assistência e proteção a menores. Coleção de leis do Brasil. Disponível em: <http://www2.camara.leg.br/ legin/fed/decret/1920-1929/decreto-17943-a-12outubro-1927-501820-publicacaooriginal-1-pe. html>. Acesso em: 10 out. 2018. 12 out. 1927.

CASSETARI, Fernanda Biava.

Os menores atrás dos grandes muros: Penitenciária da Pedra Grande, 1931-1939. Trabalho de Conclusão de Curso (Graduação em História) - Universidade do Estado de Santa Catarina, Florianópolis. 2014.

FARIA, Agripa de Castro.

Relatório do diretor do Hospital Colônia Sant'Ana. (Centro de Documentação e Pesquisa do Hospital Colônia Sant'Ana, São José). 1942.

FONSECA, Cristina M.O.

Saúde no governo Vargas, 1930-45: dualidade institucional de um bem público, v.1. Rio de Janeiro: Editora Fiocruz. 2007.

FONSECA, Cristina M.O.

A saúde da criança na política social do primeiro governo Vargas. Physis, v.3, n.2, p.97-116. 1993.

\section{FONSECA, Cristina M.O.}

Modelando a cera virgem: a saúde da criança na política social de Vargas. Dissertação (Mestrado em História) - Universidade Federal Fluminense, Niterói. 1990.

\section{FONTOURA, Arselle de A.}

Por entre luzes e sombras: Hospital Colônia Santana: (re)significando um espaço da loucura. Dissertação (Mestrado em História) - Universidade Federal de Santa Catarina, Florianópolis. 1997.

FOUCAULT, Michel.

Obrar mal, decir la verdad. Buenos Aires: Siglo XXI. 2014.
FOUCAULT, Michel.

Microfísica do poder. São Paulo: Graal. 2012.

FOUCAULT, Michel.

Naissance de la biopolitique. Paris: Gallimard. 2005.

FOUCAULT, Michel.

Securité, territoire, population. Paris: Gallimard. 2004.

FOUCAULT, Michel.

Le pouvoir psiquiatrique. Paris: Gallimard. 2003.

FOUCAULT, Michel.

Les anormaux. Paris: Gallimard. 1999.

FOUCAULT, Michel.

Il faut défendre la société. Paris: Gallimard. 1997.

FOUCAULT, Michel.

La evolución de la noción de "individuo peligroso" en la psiquiatría legal. In: Foucault, Michel. La vida de los hombres infames. Madrid: La Piqueta. p.103-117. 1996

FOUCAULT, Michel.

El juego de Michel Foucault. In: Foucault, Michel. Saber y verdad. Madrid: La Piqueta. p.127-162. 1984.

FOUCAULT, Michel.

Vigilar y castigar. México: Siglo XXI. 1979.

FOUCAULT, Michel.

La historia de la sexualidad I: la voluntad de saber. México: Siglo XXI. 1978.

FREIRE, Maria Martha de L.; LEONY, Vinícius da $S$.

A caridade científica: Moncorvo Filho e o Instituto de Proteção e Assistência à Infância do Rio de Janeiro, 1899-1930. História, Ciências, Saúde - Manguinhos, v.18, supl.1, p.199-225. 2011.

GALTON, Frances.

Natural inheritance. Nova York: Macmillan. 1889.

GARLAND, David.

O que significa escrever uma "história do presente"? Abordagem genealógica de Foucault explicada. Revista Justiça e Sistema Criminal, v.1, n.1, p.73-96. 2009.

KEHL, Renato.

Lições de eugenia. Rio de Janeiro: Francisco Alves. 1929.

KRAEPELIN, Emil.

On the question of degeneration. History of Psychiatry, v.18, n.3, p.389-398. 2007.

LIVROS DE REGISTRO...

Livros de registro de entrada de doentes. (Centro de Documentação e Pesquisa do Hospital Colônia Sant'Ana, São José). 1942. 
LIVROS DE REGISTRO...

Livros de registro de entrada de doentes. (Centro de Documentação e Pesquisa do Hospital Colônia Sant'Ana, São José). 1941.

LOBO, Lilia Ferreira.

Os infames da história: pobres, escravos e deficientes no Brasil. Rio de Janeiro: Lamparina. 2008.

LOPES, Ernani.

A alta tardia dos heredopsicopatas por motivo de ordem eugênica: subsídio para a nossa lei de assistência a psicopatas. Arquivos Brasileiros de Higiene Mental, v.6, n.4, p.277-289. 1933.

MAGNAN, Valentin.

Leçons cliniques sur les maladies mentales. Paris: Baillére. 1887.

MOREL, Benedict August.

Rapport medical sur un cas de simulation de folie. Annales Médico-psychologiques, n.3, p.61-83. 1857.

PEREIRA, Ivone.

Crianças e adolescentes pobres à sombra da delinquência e da desvalia: Florianópolis, 1900-1940. Tese (Doutorado em História) Universidade Federal do Paraná, Curitiba. 2006.

PINEL, Philippe.

Traité médico-philosophique sur l'aliénation mentale. Paris: Les Empêcheurs de Penser en Rond. [1901] 2007.

PRONTUÁRIOS...

Prontuários de menores da década de 1940

(Centro de Documentação e Pesquisa do

Hospital Colônia Sant'Ana, São José). 1940.

RIZZINI, Irene.

A criança e a lei no Brasil: revisitando a história, 1822-2000. Rio de Janeiro: Unicef; Cespi; USU. 2000.

RIZZINI, Irene.

O século perdido: raízes históricas das políticas públicas para a infância no Brasil. Rio de Janeiro: Editora Universitária Santa Úrsula; Amais. 1997.

SALLA, Fernando; BORGES, Viviane.

Prontuários de instituições de confinamento. In: Rodrigues, Rogério Rosa (Org.). Possibilidades de pesquisa em história. São Paulo: Editora Contexto. p.115-136. 2017.

SANTAELLA, Antônio.

Relatório do diretor do Hospital Colônia Sant'Ana. Relatório de gestão (Centro de Documentação e Pesquisa do Hospital Colônia Sant'Ana, São José). 1951.

\section{SANTA CATARINA.}

Guia dos serviços públicos e comunitários de saúde mental de Santa Catarina. Florianópolis: Secretaria de Estado da Saúde. 1998.
SCHWARCZ, Lilia Moritz.

O espetáculo das raças: cientistas, instituições e questão racial no Brasil, 1870-1930. São Paulo: Companhia das Letras. 1993.

SILVA. Renata Prudêncio da.

Medicina, educação e psiquiatria para a infância: o Pavilhão-Escola Bourneville no início do século XX. Revista Latino-americana de Psicopatologia Fundamental, v.12, n.1, p.195-208. 2009.

SOUZA, Filipe Brito de.

Eugenia negativa no Brasil: Renato Kehl e suas lições de eugenia. Trabalho de Conclusão de Curso (Graduação em História) - Universidade Federal do Paraná, Curitiba. 2013.

SOUZA, Vanderlei Sebastião de.

A eugenia brasileira e suas conexões internacionais: uma análise a partir das controvérsias entre Renato Kehl e Edgard Roquette-Pinto, 1920-1930. História, Ciências, Saúde - Manguinhos, v.23, supl., p.93-110. 2016.

SOUZA, Vanderlei Sebastião de.

A política biológica como projeto: a "eugenia negativa" e a construção da nacionalidade na trajetória de Renato Kehl, 1917-1932. Dissertação (Mestrado em História das Ciências e da Saúde) - Fiocruz, Rio de Janeiro. 2006a.

SOUZA, Vanderlei Sebastião de. Em nome da raça: a propaganda eugênica e as ideias de Renato Kehl nos anos 1910 e 1920. Revista de História Regional, v.11, n.2, p.29-70. 2006b.

SOUZA, Vanderlei Sebastião de.

A política biológica como projeto: a "eugenia negativa" e a construção da nacionalidade na trajetória de Renato Kehl (1917-1932). História, Ciências, Saúde - Manguinhos, v.13, n.4, p.1.0621.063. 2006c.

\section{STEPAN, Nancy.}

A hora da eugenia: raça, gênero e nação na América Latina. Rio de Janeiro: Editora Fiocruz. 2005.

VENANCIO, Ana Teresa A.

Da colônia agrícola ao hospital-colônia: configurações para a assistência psiquiátrica no Brasil na primeira metade do século XX. História, Ciências, Saúde - Manguinhos, v.18, supl.1, p.35-52. 2011.

VIANA, Bruna.

Um lugar para os ditos anormais: assistência psiquiátrica às crianças e jovens na primeira década do Hospital Colônia Sant'Ana, 19421951. Dissertação (Mestrado em História) - Universidade do Estado de Santa Catarina, Florianópolis. 2015. 
VIANNA, Adriana de Resende B.

O mal que se adivinha: polícia e menoridade no Rio de Janeiro, 1910-1920. Rio de Janeiro: Arquivo Nacional. 1999.
WEGNER, Robert; SOUZA, Vanderlei de. Eugenia "negativa", psiquiatria e catolicismo: embates em torno da esterilização eugênica no Brasil. História, Ciências, Saúde - Manguinhos, v.20, n.1, p.263-288. 2012.

\section{uuuUUU}

